\title{
A DIDATIZAÇÃO DO DISCURSO DA CIÊNCIA NA MÍDIA ELETRÔNICA ${ }^{1}$
}

\author{
Liane Beatriz Gerhardt ${ }^{2}$
}

\section{RESUMO}

A partir do objetivo principal dos artigos de Popularização da Ciência (PC) de encurtar a distância entre ciência e povo (MUELLER, 2002), por meio da linguagem acessível à audiência não especializada, os escritores lançam mão de recursos de recontextualização dos artigos científicos em notícias de PC. Tomando por base os trabalhos de Motta-Roth (2008, 2009 e 2010) e o modelo sobre as funções discursivas da reformulação, proposto por Hyland (2007), estabelecemos como objetivo, neste artigo, investigar em que medida o emprego dos recursos linguísticos de aposto e glosa colaboram para a recontextualização e a didatização do discurso da ciência. Para isso, examinamos a incidência dos recursos linguísticos de aposto e glosa em 30 notícias de PC, publicados nos sites da BBC News, Scientific American, no período de 2004 a 2008. Os resultados indicam que os recursos de pedagogização são empregados iterativamente para a explanação de princípios e conceitos por meio da inserção de informações que reorientam o leitor sobre o objeto apresentado anteriormente sob uma outra perspectiva e, também, para fazer um aporte de informações novas relativas à pesquisa; à credenciais das posições enunciativas, à instituição, pesquisadores e à revista em que foram publicados os resultados.

Palavras-chave: análise de gênero; notícia de popularização da ciência; aposto e glosa

\begin{abstract}
Considering the main objective of Science Popularization of making distances between science and people shorter (MUELLER, 2002) through easier language to the lay audience, writers use recontextualization strategies when they write science popularization news from science articles. Supported by Motta-Roth (2008, 2009 and 2010) and the discourse functions of reformulations model, by Hyland (2007), we established as objective for this article, to investigate how the use of linguistic resources of apposition and gloss contribute to the recontextualization and to the didatization of the science discourse. To do so, we examined the occurrence of the linguistic elements of apposition and gloss in 30 science popularization news published by BBC News Online and Scientific American Online, in the period of 2004 and 2008. The results point that the pedagogical resources are employed recurrently to explain principles and concepts through the insertion of information that reguide the reader on the object presented before considering a new perspective and also to add new information on the research; on the credentials of the enunciative positions, the institution, researchers, and the journal where the results were published.
\end{abstract}

Keywords: genre analysis; science popularization news; apposition and gloss

\footnotetext{
${ }^{1}$ Este artigo aborda resultados parciais da tese de doutorado A didatização do discurso da ciência na mídia eletrônica, orientada pela Professora Dr. Désirée Motta-Roth.

${ }^{2}$ Doutoranda do Programa de Pós Graduação em Letras da Universidade Federal de Santa Maria; Professora do Instituto Federal de Educação, Ciência e Tecnologia de Santa Catarina, campus avançado Xanxerê.
} 


\section{INTRODUÇÃO}

Nas últimas décadas, percebemos uma aceleração expressiva do processo de popularização da ciência por meio da mídia, centros e museus de ciência, eventos de divulgação. Entretanto, observamos, também, fragilidade e limitação nesse esforço, no sentido de que o conhecimento construído nas academias e centros de pesquisa, por exemplo, não tem chegado ao seu destino final, o público não-especialista. Essa fragilidade e limitação são justificadas, em parte, pela ausência de políticas públicas bem definidas, pela atuação restrita, embora crescente, das universidades, institutos de pesquisa, de organismos públicos e escolas (MINISTÉRIO DA CIÊNCIA E TECNOLOGIA, 2006).

Ao esforço de popularizar a ciência por meio de canais tradicionalmente conhecidos como documentários e livros tem se somado o jornalismo científico de massa, o qual tem se especializado consideravelmente na produção de textos de popularização científica, (doravante PC), que figuram na mídia eletrônica como New Scientist, Scientific American, Popular Science entre outras, passando a constituir uma das principais fontes de conhecimento científico para o público não-especialista. Os textos de PC apresentam a pesquisa como notícia, focam a exclusividade e a generalidade da descoberta científica em um tom de autoridade factual, criando para a informação científica um contexto retórico muito diferente daquele encontrado em um texto de literatura científica em termos de padrões organizacionais e negociação com leitores (HYLAND, 2009, p. 164).

Nesse meio, podemos entender a popularização da ciência em conformidade com Pagano (1998), que a define como um processo de des-especialização do conteúdo informativo, realizado pela reescrita do texto, envolvendo a produção de um discurso estruturado com nexos coesivos explícitos e a frequente utilização de recursos (metáforas, personificações, etc) que visam uma divulgação mais didática da informação científica. Nessa direção, “o jornalista-autor passa a ser o mediador da interação entre cientista e público e também o construtor e articulador de um número variado de discursos que ultrapassam os limites do discurso acadêmico” (BEACCO et al., 2002, p. 282 apud MOTTA-ROTH; LOVATO, 2009, p. 237).

Para Leibruder, os textos de PC surgem da intersecção dos gêneros científico e jornalístico e, por isso, apresentam características linguísticas de ambos, ou seja, a objetividade da ciência de um lado e, por outro, um registro menos formal, mais fluido e próximo da linguagem coloquial (LEIBRUDER, 2000, p. 234). Neste trabalho, tendo em vista nosso objetivo, exposto logo a seguir, optamos pela definição de notícia de PC como: 
um texto que relata a realização de uma pesquisa recente de interesse para a comunidade-alvo da publicação (site), incluindo a manchete/o título, o lide, a pesquisa propriamente dita, o seu contexto, as pesquisas prévias, os resultados e o significado destes para a comunidade” (MARCUZZO; MOTTA-ROTH, 2008, p. 3).

Nesse processo, para que os leitores não-especialistas tenham acesso ao conhecimento especializado, o discurso de popularização precisa ser formulado de maneira que seja possível a integração do conhecimento prévio desse leitor com o conhecimento especializado (CALSAMIGLIA; VAN DIJK, 2004, p 370). Para tornar isso possível, o jornalista lança mão de várias estratégias com o intuito de incorporar ao texto elementos linguísticos e extralinguísticos da possível experiência da audiência. O texto passa a ter um caráter autoexplicativo a partir do emprego de recursos de reescritura dos artigos científicos em notícias de PC (HYLAND, 2007).

Este trabalho integra o Projeto CNPq (nº 301962/2007-3), intitulado Análise crítica de gêneros com foco em artigos de popularização da ciência, idealizado e coordenado pela Professora Dra Désirée Motta-Roth, realizado no Labler - Laboratório de Leitura e Redação da UFSM, vinculado ao GRPesq/CNPQ - Grupo de Pesquisa “Linguagem como Prática Social”, do Programa de Pós-Graduação em Letras da UFSM. Esse trabalho tem como objetivo investigar diferentes aspectos do processo de popularização da ciência com foco no gênero notícia de PC veiculada na internet.

Neste artigo, focamos o processo de reformulação por meio do emprego de aposto e glosa. A literatura publicada sobre o tema (CIAPUSCIO, 2003; HYLAND, 2005, 2007, 2009; LEIBRUDER, 2000; VANDE KOPPLE, 1985, CUENCA; BACH, 2007), bem como as análises prévias já realizadas (PRATES; SCHERER; MOTTA-ROTH; NASCIMENTO, 2008; MOTTA-ROTH; GERHARDT; LOVATO, 2008; MOTTA-ROTH; LOVATO, 2009; GERHARDT, 2009, MOTTA-ROTH, 2009) corroboram a existência e a importância desses recursos, pois produzir um texto de popularização da ciência significa basicamente recontextualizar e reformular uma fonte de modo que a mesma seja compreensível e relevante para uma outra audiência, em um contexto discursivo que, apesar de previsível, difere daquele da fonte original (CIAPUSCIO, 2003, p. 210).

A partir dos trabalhos de Motta-Roth (2008, 2009 e 2010) e do modelo proposto por Hyland (2007), estabelecemos como objetivo, neste artigo, investigar em que medida o emprego dos recursos linguísticos de aposto e glosa colaboram para a recontextualização e a didatização do discurso da ciência. 


\section{REFERENCIAL TEÓRICO}

\subsection{Popularização da ciência}

$\mathrm{Na}$ literatura sobre popularização do conhecimento científico, podemos identificar duas visões: uma tradicional e outra contemporânea. A diferença entre ambas pode ser resumida em três aspectos. Primeiro, na tradicional, a ciência é considerada uma fonte ativa de conhecimento e a audiência é vista como receptora desinformada e passiva (WHITLEY, 1985 apud MILLER, 2009, p. 260). Segundo, a popularização é vista como externa ao processo de produção e validação do conhecimento, o que a caracterizaria como uma atividade de não cientistas, os leigos. Isso significa que na visão tradicional a disseminação do conhecimento científico por parte de cientistas às audiências de não-cientistas é vista como uma atividade que não contribui com a reputação do pesquisador. Terceiro, o modelo tradicional defende uma noção de conhecimento científico puro, genuíno que contrasta com o conhecimento popularizado, as diferenças entre conhecimento genuíno e popularizado são tidas como distorções e degradações produzidas por jornalistas e público leigo (HILGARTNER, 1990).

A visão contemporânea de popularização do conhecimento científico desafia os três aspectos acima expostos ao reconhecer a diversidade da audiência e as atitudes da mesma em relação à ciência. A pesquisa sociológica mostra que membros de audiências diversas constroem percepções diferentes em relação ao conhecimento científico (MICHAEL, 1996 apud MILLER, 2009, p. 260). Nessa visão, a popularização tem um papel ativo no processo de produção e geração do conhecimento: primeiro para conseguir apoio da sociedade e do governo, os cientistas precisam simplificar o conhecimento científico, popularizá-lo e enfatizar seu valor prático (WHITLEY, 1985 apud MILLER, 2009, p. 260). Ao atingir e conquistar a opinião pública, a popularização permite que a ciência seja debatida por diferentes segmentos da sociedade: centros de pesquisa, universidades, governo, empresas privadas, órgãos não-governamentais, público geral, proporcionando aprendizagem e formação de opiniões (BEACCO et al., 2002 apud MOTTA-ROTH; LOVATTO, 2009, p. 247). 
Além disso, no modelo contemporâneo, (HILGARTNER, 1990, p. 532-24), há um feedback do texto de PC para a comunidade científica por meio das referências de textos de PC, feitas nos textos científicos como forma de legitimação da popularização. Outra maneira de feedback entre popularização e comunidade científica ocorre por meio da comunicação entre cientistas e jornalistas, o que permite que descobertas recentes sejam conhecidas antes de aparecerem em publicações da comunidade científica em forma de artigo científico. Nesses casos, muitas vezes, a comunidade científica discute e forma opinião a partir da notícia de PC.

Outra característica marcante do modelo contemporâneo é a negação da distinção entre conhecimento científico genuíno e distorcido, por se acreditar que o conhecimento é construído, circula, é validado e é consumido dentro de um determinado contexto social, num processo de negociação constante da comunidade de prática. Diferentes comunidades podem oferecer, portanto, diferentes formas de conhecimento sem que uma invalide a outra.

Nessa linha de raciocínio, nos encaminhamos à perspectiva Sociorretórica de Bazerman, a qual nos parece compatível com essa nova visão contemporânea pelo fato de seu ponto central de análise partir da interação na situação histórico-cultural, levando em conta a realidade social no estudo de conjuntos de gêneros, sistemas de gêneros e atividades, sem se prender às formas de cada um. Nesse caso, o autor propõe um estudo de gênero que envolve também um estudo da circulação de discursos em termos de meios, canais, modos retóricos e tipificação.

Nesse viés, temos instrumentos conceituais e analíticos que permitem examinar o trabalho realizado pelo texto na sociedade. Sua abordagem analítica discute os conceitos de fatos sociais, atos de fala, gêneros, sistemas de gêneros e sistemas de atividades, os quais sugerem como as pessoas criam novas realidades de significação, relações e conhecimento, fazendo uso de textos (BAZERMAN, p.19, 2005). O texto organiza as ações cotidianas dos seus usuários, que por sua vez criam significações e fatos sociais num processo interativo tipificado num sistema de atividades que envolvem as ações discursivas.

Cada texto bem sucedido cria para seus leitores um fato social. Os fatos sociais consistem em ações sociais significativas realizadas pela linguagem, ou atos de fala. Esses atos são realizados através de formas textuais padronizadas, típicas e, portanto, inteligíveis, ou gêneros, que estão relacionados a outros textos e gêneros que ocorrem em circunstâncias relacionadas. Juntos, os vários tipos de textos se acomodam em conjuntos de gêneros dentro de sistemas de gêneros, os quais fazem parte dos sistemas de atividades humanas. (BAZERMAN, p.22, 2005) 
Todo esse contexto revela que a notícia de PC tem como aspecto essencial seu caráter didático, de educação e expansão de horizontes das massas, proporcionado pela ciência, definida pelo romancista Britânico Ian McEwan (2007 apud HYLAND, 2009, p. 158) como uma "maravilhosa forma de engajamento com o mundo, importante demais para ser retida somente por cientistas.” Esse caráter é alcançado, em parte, pelo fato de a notícia de PC apresentar em sua estrutura retórico-discursiva estratégias de reescritura, tais como aposto e glosa, que funcionam como reformuladores de ideias e/ou termos científicos, conforme discutido a seguir.

\subsection{Os recursos de recontextualização por aposto e glosa na didatização do discurso da ciência}

A partir da definição de Pagano (1998) para o processo de popularização da ciência, apresentado anteriormente, e dos trabalhos de Motta-Roth (2009a, 2009b, 2009c, 2010a, 2010b), Motta-Roth; Marcuzzo (no prelo) sobre recontextualização no gênero notícia de PC na mídia eletrônica, recorremos ao conceito de recontextualização de Bernstein (1996) quando se refere à produção do discurso pedagógico. Para o autor, o discurso pedagógico é “um princípio que tira (desloca) um discurso de sua prática e contexto substantivos e reloca aquele discurso de acordo com seu próprio princípio de focalização e reordenamento seletivos” (BERNSTEIN, 1996, p. 259). A partir disso, podemos afirmar que no caso da notícia de PC, o discurso científico é retirado de sua rede de princípios e significados e recolocado a partir das finalidades e princípios do processo de popularização da ciência.

Bernstein (Ibid.) refina o conceito de discurso pedagógico ao declarar que:

Trata-se de um princípio recontextualizador que, seletivamente, apropria, reloca, refocaliza e relaciona outros discursos, para constituir sua própria ordem e seus próprios ordenamentos. Neste sentido, o discurso pedagógico não pode ser identificado com quaisquer dos discursos que recontextualiza. Ele não tem qualquer discurso próprio que não seja um discurso recontextualizador (BERNSTEIN, 1996, p. 259).

Nesse caso, o discurso pedagógico é visto por Bernstein como um discurso particular, que se apropria de outros discursos em função de suas necessidades, essa é uma das características dos textos de PC, os quais têm o caráter de facilitação ou didatização do conteúdo científico em linguagem para o público não-especialista. Em termos linguísticos, são utilizadas estratégias de recontextualização como o uso de metáforas, personificações, 
aposto e glosa (PAGANO, 1998; GOMES, 2000; COLUSSI, 2002, LEIBRUDER, 2000, SANTOS, 2010). Aqui, devido à especificidade do trabalho, abordaremos o papel do aposto e das glosas no processo de recontextualização dos artigos científicos para notícia de PC.

O aposto tem sido tratado no ensino tradicional de gramática de modo essencialmente voltado ao âmbito da sintaxe da oração, ou seja, limitado aos aspectos formais, apenas com o objetivo de identificação e classificação, o que nos parece vago e muito restritivo, tendo em vista que a relação de significado pode ultrapassar os limites da sentença e, inclusive, do próprio texto. Esse tratamento não nos parece muito produtivo, já que as estruturas apositivas são formalmente diversas e multifuncionais, utilizadas pelos usuários na construção de sentido. No caso da reformulação, percebemos que as construções apositivas refletem opções feitas pelos escritores, no caso da PC, dos jornalistas, visando à produção de certos efeitos de sentido que o moldam de acordo com os objetivos do escritor em relação a sua audiência. Quanto à glosa, observamos que seu uso tradicional remete a um conceito de tradução de uma palavra rara ou incomum (DUBOIS et al., 1993, p. 308, 09), sem que haja uma relação com a paráfrase ou com a especificação comumente empregadas na reformulação.

Halliday e Matthiessen (2004, p. 395-96) concebem a expansão de uma oração em relação à outra por meio da elaboração e da extensão. Na elaboração, uma oração não acrescenta novos elementos à mensagem, adiciona informação sobre o que já foi dito por meio de especificação ou descrição. No caso da extensão, ao contrário da elaboração, uma segunda unidade expande o significado de uma unidade anterior ao acrescentar informação nova ou qualificá-la por meio de referência a tempo, modo, lugar, condição, etc.

Considerando o objetivo do trabalho, optamos por uma perspectiva metadiscursiva de compreensão do processo de recontextualização por acreditarmos que o metadiscurso é autoreflexivo que faz referência ao texto em construção ou ao escritor e ao possível leitor desse texto, agindo na conexão, organização e interpretação do material, tendo em vista a compreensão e os valores de uma determinada comunidade discursiva (HYLAND, 2000 apud HYLAND, 2007, p. 268). Nesse trabalho, a reformulação por expansão, aposto, e por redução, glosa, são exemplos de estratégias metadiscursivas empregadas pelo jornalista com o intuito de garantir que o leitor tenha condições de recuperar o significado pretendido pelo escritor.

No modelo proposto por Hyland (2007), tanto o aposto quanto a glosa são opções retóricas feitas pelos escritores com o intuito de atingir o engajamento do leitor por meio da clareza. O escritor tenta identificar possíveis pontos do texto que poderão constituir 
problemas de compreensão e, a partir daí, partes do texto são reescritas. Isso ocorre com o objetivo de moldar o significado de acordo com a intenção do escritor, relacionando o texto à experiência do leitor, ao seu conhecimento prévio (HYLAND, 2007, p. 266).

Hyland (2007) afirma que esses aspectos caracterizam a glosa, definida pelo autor como "itens que fornecem informação adicional por meio dos recursos de paráfrase, explicação ou elaboração do que foi dito para garantir que o leitor consiga recuperar o significado pretendido pelo escritor” (Ibid, p. 268). A glosa tem o objetivo básico de negociar significado tanto na oralidade quanto na escrita com duas subfunções: a reformulação e a exemplificação (Ibid.). A reformulação é definida como uma função discursiva na qual a segunda unidade é uma reafirmação ou elaboração da primeira, escrita em outras palavras para apresentar um ponto de vista diferente ou simplesmente para reforçar a mensagem (Ibid, p. 269).

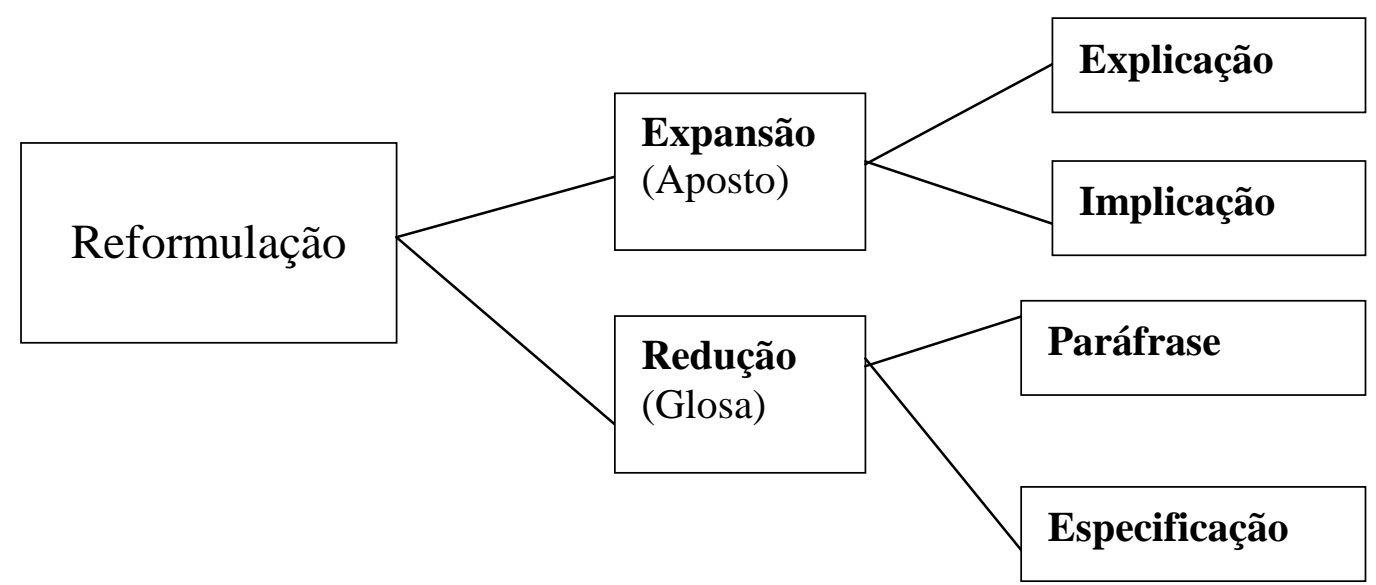

Figura 1 - Funções discursivas de reformulação (HYLAND, 2007, p.274) ${ }^{3}$

Podemos observar, com o auxílio da figura 1, que no caso das reformulações por expansão, ocorre uma reafirmação de uma ideia por meio da ampliação do sentido pretendido pelo escritor. Isso ocorre pela explicação, quando o escritor insere informações pontuais para fins de esclarecimento que elaboram o significado de uma unidade anterior com o intuito de tornar um princípio, conceito ou uma nomenclatura mais acessível (Ibid, p. 274), ou por implicação, quando o segmento anterior é retomado para concluir ou resumir (Ibid, p. 275).

3 Os parênteses nos itens de Expansão e Redução com as indicações de aposto e glosa foram acrescentadas à figura. 
No caso da reformulação por redução, a didatização ocorre pelo estreitamento de significado em relação ao que foi dito antes por meio da paráfrase ou da especificação (Ibid, p. 275 - 76).

\section{METODOLOGIA}

\subsection{Procedimentos de identificação dos sites}

Os sites dos quais foram extraídos os textos que compõem o corpus foram selecionados a partir dos critérios definidos por (MOTTA-ROTH, 2007), descritos no item 2.2 abaixo. O contexto dos sites foi investigado a partir do monitoramento semanal durante o período de 15 dias, quando foi observada a dinâmica de atualização da seção news, temas, número de notícias publicadas, período de disponibilidade gratuita no site. Foram selecionados os seguintes sites: www.bbc.co.uk e www.sciam.com

\subsection{Procedimentos de coleta do corpus}

O corpus da pesquisa é composto por 30 notícias de PC, conforme os quadros 1 e 2, coletadas de acordo com os critérios estabelecidos por (MOTTA-ROTH, 2008):

a) público-alvo: escritas para uma audiência leiga ou de não-especialistas;

b) mídia: disponíveis on-line, devido à gratuidade e à acessibilidade;

c) línguas: publicações escritas em língua inglesa;

d) período de tempo: publicadas entre 2004 e 2008;

e) conteúdo: notícias que reportam pesquisas científicas relacionadas aos temas transversais de saúde, meio ambiente e tecnologia, conforme Parâmetros Curriculares Nacionais (BRASIL, 1997a; 1997b; 1997c; 1997d).

O corpus foi dividido em dois subcorpora de 15 textos, BBCNEWS, SCIAM, , identificados nos quadros 1, 2, respectivamente, coletados nas seções de News de cada site.

\begin{tabular}{|l|l|}
\hline BBC \# 1 & $\underline{\text { http://news.bbc.co.uk/2/hi/health/7324555.stm }}$ \\
\hline BBC \# 2 & $\underline{\text { http://news.bbc.co.uk/2/hi/health/7287792.stm }}$ \\
\hline BBC \# 3 & $\underline{\text { http://news.bbc.co.uk/2/hi/science/nature/7324654.stm }}$ \\
\hline BBC \# 4 & $\underline{\text { http://news.bbc.co.uk/2/hi/science/nature/4046427.stm }}$ \\
\hline BBC \# 5 & $\underline{\text { http://news.bbc.co.uk/2/hi/health/7319251.stm }}$ \\
\hline BBC \# 6 & $\underline{\text { http://news.bbc.co.uk/2/hi/health/7443534.stm }}$ \\
\hline BBC \# 7 & $\underline{\text { http://news.bbc.co.uk/2/hi/health/6977423.stm }}$ \\
\hline
\end{tabular}




\begin{tabular}{|l|l|} 
BBC \# 8 & $\underline{\text { http://news.bbc.co.uk/2/hi/health/6483403.stm }}$ \\
\hline BBC \# 9 & $\underline{\text { http://news.bbc.co.uk/2/hi/health/6655221.stm }}$ \\
\hline BBC \# 10 & $\underline{\text { http://news.bbc.co.uk/2/hi/health/4632886.stm }}$ \\
\hline BBC \# 11 & $\underline{\text { http://news.bbc.co.uk/2/hi/health/7445606.stm }}$ \\
\hline BBC \# 12 & $\underline{\text { http://news.bbc.co.uk/2/hi/health/7075511.stm }}$ \\
\hline BBC \# 13 & $\underline{\text { http://news.bbc.co.uk/2/hi/health/7208941.stm }}$ \\
\hline BBC \# 14 & $\underline{\text { http://news.bbc.co.uk/2/hi/uk_news/england/7317745.stm }}$ \\
\hline BBC \# 15 & $\underline{\text { http://news.bbc.co.uk/2/hi/health/7380567.stm }}$ \\
\hline
\end{tabular}

Quadro 1 - Numeração e endereço eletrônico das notícias do subcorpus da BBCNEWS

\begin{tabular}{|l|c|}
\hline SCIAM \# 1 & http://www.sciam.com/article.cfm?id=when-it-comes-to-photosynthesis-plants- \\
\cline { 2 - 3 } & perform-quantum-computation \\
\hline SCIAM \# 2 & http://www.sciam.com/article.cfm?id=whole-lotta-shakin-on-ast \\
\hline SCIAM \# 3 & http://www.scientificamerican.com/article.cfm?id=bioelectricity-versus-biofuel \\
\hline SCIAM \# 4 & http://www.sciam.com/article.cfm?id=growing-prostate-glands-from-stem-cells \\
\hline SCIAM \# 5 & http://www.sciam.com/article.cfm?id=mathematics-point-the-w \\
\hline \multirow{2}{*}{ SCIAM \# 6} & http://www.sciam.com/article.cfm?id=a-tale-of-two-exoplanets-one- incredibly- \\
\cline { 2 - 3 } & hot-the-other-extremely-windy \\
\hline \multirow{2}{*}{ SCIAM \# 7} & ttp://www.sciam.com/article.cfm?id=genetically-modified-crops-survive-weed- \\
\cline { 2 - 3 } & whacking-herbicide \\
\hline SCIAM \# 8 & http://www.sciam.com/article.cfm?id=is-the-out-of-africa-theory-out \\
\hline SCIAM \# 9 & http://www.sciam.com/article.cfm?id=did-sesame-street-have-it-right \\
\hline SCIAM \# 10 & http://www.sciam.com/article.cfm?id=that-flu-you-caught-it-ca \\
\hline SCIAM \# 11 & http://www.sciam.com/article.cfm?id=monkey-think-robot-do \\
\hline SCIAM \# 12 & http://www.sciam.com/article.cfm?id=new-study-links-exercise-to-longevity \\
\hline SCIAM \# 13 & ttp://www.sciam.com/article.cfm?id=wireless-energy-lights-bulb-from-seven- \\
\cline { 2 - 3 } & feet-away \\
\hline SCIAM \# 14 & http://www.sciam.com/article.cfm?id=cave-speak-did-neandertal \\
\hline SCIAM \# 15 & http://www.sciam.com/article.cfm?id=is-human-growth-hormone-t \\
\hline Q
\end{tabular}

Quadro 2- Numeração e endereço eletrônico das notícias do subcorpus da SCIAM

\subsection{Procedimentos de análise}

A análise dos dados foi quantitativa e qualitativa com o cruzamento dos dados levantados em cada texto e em cada revista para que se tornasse possível a interpretação dos mesmos.

Primeiramente, os textos foram lidos individualmente para a identificação e interpretação dos casos de aposto e glosa em cada texto e em cada revista, de acordo com as definições propostas por HYLAND (2007). Essa etapa demonstrou a incidência desses 
elementos de reformulação em cada texto e em cada revista individualmente e permitiu que chegássemos a algumas generalizações com relação às funções dessas estratégias no texto de PC em cada mídia.

\section{RESULTADOS}

A análise das 30 notícias de PC apontou a presença significativa de elementos de recontextualização por meio de reformulação por expansão ou redução, conforme (Tabelas 1 e 2), o que nos permite afirmar que a preocupação com o aspecto de didatização do conteúdo científico em linguagem mais simples para o público não-especialista parece ser característica do gênero por estar presente em todos os textos que compõem o corpus, fato corroborado pela definição de popularização da ciência de Pagano (1998), adotada neste trabalho.

Tabela 1 - Incidência das funções discursivas de reformulação nos textos da BBC News.

\begin{tabular}{|c|c|c|c|c|c|}
\hline Texto & $\begin{array}{l}\text { Expansão por } \\
\text { explicação }\end{array}$ & $\begin{array}{l}\text { Expansão por } \\
\text { implicação }\end{array}$ & $\begin{array}{l}\text { Redução } \\
\text { por } \\
\text { paráfrase } \\
\end{array}$ & $\begin{array}{c}\text { Redução } \\
\text { por } \\
\text { especificação } \\
\end{array}$ & TOTAL \\
\hline BBC\#1 & + & + & + & + & 16 \\
\hline BBC\#2 & + & + & & & 5 \\
\hline BBC\#3 & + & & & + & 10 \\
\hline BBC\#4 & + & & & + & 14 \\
\hline ВBC\#5 & + & + & & + & 11 \\
\hline BBC\#6 & + & & + & + & 11 \\
\hline BBC\#7 & + & & + & + & 4 \\
\hline BBC\#8 & + & & + & + & 8 \\
\hline BBC\#9 & + & + & & + & 10 \\
\hline BBC\#10 & + & + & & + & 4 \\
\hline BBC\#11 & + & & + & + & 6 \\
\hline BBC\#12 & + & & & & 6 \\
\hline BBC\#13 & + & + & & & 6 \\
\hline BВC\#14 & + & & & + & 8 \\
\hline BBC\#15 & + & & + & + & 10 \\
\hline
\end{tabular}


Tabela 2 - Incidência das funções discursivas de reformulação nos textos da Scientific American.

\begin{tabular}{|c|c|c|c|c|c|}
\hline Texto & $\begin{array}{l}\text { Expansão por } \\
\text { explicação }\end{array}$ & $\begin{array}{l}\text { Expansão por } \\
\text { implicação }\end{array}$ & $\begin{array}{c}\text { Redução por } \\
\text { paráfrase }\end{array}$ & $\begin{array}{l}\text { Redução por } \\
\text { especificação }\end{array}$ & TOTAL \\
\hline SCIAM\#1 & + & & & + & 4 \\
\hline SCIAM\#2 & + & & & & 3 \\
\hline SCIAM\#3 & + & & + & + & 10 \\
\hline SCIAM\#4 & + & & & + & 8 \\
\hline SCIAM\#5 & + & & & + & 5 \\
\hline SCIAM\#6 & + & + & + & + & 9 \\
\hline SCIAM\#7 & + & & & + & 11 \\
\hline SCIAM\#8 & + & + & & & 4 \\
\hline SCIAM\#9 & + & + & & + & 8 \\
\hline SCIAM\#10 & + & & + & + & 10 \\
\hline SCIAM\#11 & + & & + & + & 8 \\
\hline SCIAM\#12 & + & & + & + & 7 \\
\hline SCIAM\#13 & + & & + & + & 9 \\
\hline SCIAM\#14 & + & & & + & 14 \\
\hline SCIAM\#15 & + & & & & 13 \\
\hline
\end{tabular}

\section{Casos de reformulação por site}




\begin{tabular}{|l|c|c|c|c|c|} 
& Explicação & Implicação & Paráfrase & Especificação & \\
\hline $\begin{array}{l}\text { BBC } \\
\text { News }\end{array}$ & 79 & 8 & 12 & 30 & 129 \\
\hline Sci Am & 77 & 4 & 11 & 32 & 124 \\
\hline Total & 156 & 12 & 23 & 62 & 253 \\
\hline
\end{tabular}

Outro aspecto característico no corpus analisado é o emprego iterativo das estratégias de expansão e redução para a explanação de princípios e conceitos, demonstrando um interesse constante do escritor em negociar significado com o leitor. No modelo que adotamos para analisar a recontextualização da ciência em notícias de PC, a expansão pode se dar por explicação ou por implicação enquanto que a redução é empregada por meio de paráfrase ou especificação de acordo com a ilustração feita na figura 1. Esse fenômeno está ilustrado nos exemplos 1 a 14, nos quais o escritor antevê possíveis problemas de compreensão por parte do leitor e tenta evitá-los (HYLAND, 2007, p. 267).

Ao observarmos o quadro 3, vemos que existe uma preferência acentuada pela expansão em relação à implicação, elaborada por meio da explicação. Ambos os recursos constituem construções apositivas, diferentemente da redução em que são utilizadas glosas por meio de paráfrase ou especificação.

O jornalista, ao empregar a expansão por explicação, insere informações que reorientam o leitor sobre o objeto apresentado anteriormente sob uma perspectiva diferente e, também, para fazer um aporte de informações novas, como pode ser observado no exemplo 1, em que o jornalista acrescenta informações relativas à metodologia da pesquisa; introduz credenciais das posições enunciativas, conforme exemplo 2; indica onde a pesquisa foi feita, exemplo 3; onde foram publicados ou apresentados os resultados, exemplo 4, como forma de atribuir autoridade, crédito à opinião de um pesquisador, a um grupo de pesquisadores ou uma instituição. Esse aspecto além de caracterizar uma marca do processo de popularização da ciência, evidencia a participação do jornalista como “mobilizador de debates públicos" (MOIRAND, 2003). Esses aspectos são corroborados em trabalhos como: (MOTTA-ROTH, D; GERHARDT, L; LOVATO, C. 2008b, MOTTA-ROTH, D. 2009, PRATES, N. D.; SCHERER, A. S.; MOTTA-ROTH, D. 2008, MOTTA-ROTH, D.; LOVATO, C. dos S. 2009, MARCUZZO P., 2009a, b; MOTTA-ROTH, D., 2008). 
Exemplo 1: Tina D'Hertefeldt from Lund University led the team of scientists that scoured the small field, which had hosted the GM trial 10 years ago, looking for "volunteers" - plants that have sprung up spontaneously from seed in the soil (BBC \# 3, § 4).

Exemplo 2: Professor Mark Westoby, a plant ecologist from Macquarie University in Australia, had a more blunt assessment (BBC \# 3, § 29).

Exemplo 3: Now biophysicists at the University of California, Berkeley, have shown that plants use the basic principle of quantum computing-the exploration of a multiplicity of different answers at the same time-to achieve near-perfect efficiency (SCIAM \# 1, § 1).

Exemplo 4: The environmental case for ethanol from corn continues to weaken. Turning the food crop into ethanol would not be the best use of the energy embedded in the kernels' carbohydrates, according to a new study in Science (SCIAM \# 3, § 1).

Com relação às construções apositivas, Motta-Roth (2009) aponta a adoção de tal princípio “para explicar a inserção de hiperlinks (como Science, exemplo 4) ao longo de todos os textos da Scientific American, como explicação que acrescenta informação adicional a uma proposição que já tem sentido completo.” (MOTTA-ROTH, D., 2009, p. 45). Outro aspecto essencial do processo de popularização do conhecimento científico, garantido, de modo especial, pelo emprego da expansão por explicação é a explanação de princípios, exemplo 5; efeitos, exemplo 6; conceitos, exemplo 7; também apontado em estudos anteriores (MOTTAROTH, D; GERHARDT, L; LOVATO, C. 2008b, MOTTA-ROTH, D., 2009, PRATES, N. D.; SCHERER, A. S.; MOTTA-ROTH, D., 2008, MOTTA-ROTH, D.; LOVATO, C. dos S. 2009), e expressões metafóricas, exemplo 8, em que podemos ver aspectos tipicamente científicos sendo didatizados.

Exemplo 5: HD 149026 b was already an oddball among hot Jupiters for its Saturn-like size and mass and its high density. More than two thirds of the planet must consist of elements heavier than helium, which are uncommon in gas giant planets and may introduce unexpected compounds into the atmosphere that contribute to the still mysterious total absorption, Harrington says (SCIAM \# 6, § 11). 
Exemplo 6: Physicists have known for more than a century that a moving magnetic field produces an electric field and vice versa in an effect called electromagnetic induction, which makes motors turn and allows your, say, electric toothbrush to recharge when placed on its base station (SCIAM \# 13, § 2).

Exemplo 7: The berries contain a cocktail of chemical compounds including anthocyanins which cause the deep colour in blue and purple fruits - and polyphenolics - which can be found in red wine and chocolate (BBC \# 10, § 8).

Exemplo 8: "The method of shaking is rather novel," he says, compared with earthly phenomena such as the so-called "Brazil nut effect," in which larger nuts rise to the top of a shaken can of mixed nuts (SCIAM \# 2, § 11).

O modelo de Hyland (2007) contempla, em termos de elaboração apositiva, a expansão por implicação, utilizada para introduzir uma conclusão ou para importar os aspectos principais do segmento anterior (Ibid. p. 275). No caso da PC, constitui uma estratégia importante por sinalizar à audiência que aspectos são relevantes para garantir a compreensão na progressão do texto, conforme exemplo 9. A implicação pode ocorrer dentro de um período, exemplo 9; ou entre parágrafos, exemplo 10.

Exemplo 9: Infrared data had pegged three other exoplanets, including HD $189733 \mathrm{~b}$, in the 1,000-to-1,200-kelvin range, which implied that the planets reflected about 30 percent of incoming starlight (Sci Am \# 6, \& 7).

Exemplo 10: "It's been known for some time that oilseed rape is a bit of a problem because of the survival of its seed," he told BBC News (BBC \# 3, § 13).

"It means that if farmers want to swap [from growing GM rape] to conventional varieties, they will have to wait for a number of years" (BBC \# 3, § 4).

Na reformulação por redução, a pedagogização é feita por meio da restrição do significado em relação ao que foi exposto anteriormente, há um estreitamento do escopo de interpretação (HYLAND, 2007, p.275). Pode se dar por paráfrase ou especificação, caracterizando, em oposição ao aposto, a glosa, já que temos elaboração e não expansão de 
significado. No caso da paráfrase, o escritor reafirma a idéia anterior utilizando diferentes palavras como uma forma de facilitar a compreensão e fornecer um resumo (Ibid. p. 276), num processo próximo da sinonímia. Nos exemplos 11 e 12, percebemos claramente esse fenômeno em que o objetivo é restringir as possibilidades de interpretação pelo leitor (Ibid. p. 275). Nesse caso, podemos dizer que há uma tradução de uma palavra rara ou do jargão científico para o discurso cotidiano.

Exemplo 11 - [...] looking for "volunteers" - plants that have sprung up spontaneously from seed in the soil ( $B B C \# 3, \& 5)$.

Exemplo 12 - The disruption to the body's circadian rhythm - the natural cycle that governs sleep and wakefulness - can be one of the most difficult of dementia symptoms for carers to cope with (BBC \# 11,\$5).

Na recontextualização por redução ou glosa, observamos, ainda, a ocorrência da especificação, na qual o jornalista faz o detalhamento de elementos essenciais para a compreensão da afirmação anterior, de forma a restringir, assim como na paráfrase, a interpretação dos mesmos pelo leitor (HYLAND, 2007, p. 276). Vejamos os exemplos:

Exemplo 13: They were broken down into three sub-sections: planned home birth, unplanned home birth - when a mother intended to go to hospital but was caught unawares, and a transferred group - when women who had planned a home birth ended up giving birth in hospital ( BBC \# 1, § 7).

Exemplo 14: An industry organisation, the International Service for the Acquisition of Agribiotech Applications (ISAAA), calculated recently that more than one million square kilometres of land across the world are now dedicated to growing GM plants ( $\mathrm{BBC} \# 3$, $\S$ 16).

A função de didatização é desempenhada diferentemente nas revistas, parece acompanhar o interesse da instituição em relação à ciência e, principalmente a diferentes audiências desde público não especialista a cientistas de diferentes áreas. Esse aspecto é visível se observarmos a mobilização de diferentes segmentos da sociedade para avaliar os resultados e as implicações dos mesmos no cotidiano das pessoas. Na Scientific American, são 
invocados pesquisadores e profissionais, o que demonstra um caráter mais acadêmico, enquanto que nos textos da $B B C$ News são chamados à discussão além de profissionais, os cidadãos comuns, apontando uma preocupação com uma audiência menos especializada. A análise do contexto dessas duas mídias corrobora a distinção, pois a BBC é de propriedade do Governo Britânico, de caráter público e independência editorial, financiada pelos usuários através da Licença de TV, TV Licence, ou seja, todo domicílio do Reino Unido com televisão deve pagar anualmente em torno de 126 libras, aproximadamente $€$ 181,00 (informação obtida no site da BBC). Já a Scientific American não tem esse vínculo e se caracteriza pelo interesse em ciência num nível mais especializado como pode ser observado na seção about us do site.

Outro aspecto interessante na comparação das mídias está relacionado com a função dos elementos de recontextualização. Enquanto que no corpus da $B B C$ observamos que a expansão é empregada majoritariamente para indicar credenciais das posições enunciativas, na Scientific American, esses elementos são utilizados com uma incidência maior para negociar significado relativo a princípios e conceitos científicos.

Todos os aspectos acima abordados, de um modo geral, apontam para a intenção de socialização do conhecimento científico do escritor, o jornalista, que procura, dessa forma, atingir a população que não se insere na comunidade acadêmica ou na científica com um texto que constitui uma recontextualização de pesquisas publicadas em artigos científicos, ampliando, com essa iniciativa, a audiência da ciência, colaborando com o movimento antielitista da ciência.

\section{CONSIDERAÇÕES FINAIS}

Neste artigo, procuramos investigar em que medida o emprego dos recursos linguísticos de aposto e glosa colaboram para a recontextualização e a didatização do discurso da ciência e notamos que a opção por essas estratégias está relacionada à uma preocupação do locutor, o jornalista, em comunicar com uma audiência de não especialistas. Essa constatação nos remete a Bernstein quando define “o discurso pedagógico como as regras para embutir e relacionar dois discursos” (BERNSTEIN, 1996, p. 258), pois percebemos que existe um esforço em fazer com que o discurso hermético da ciência seja recontextualizado, pedagogicamente tratado para alcançar o cidadão não especialista por meio de um discurso 
mais próximo do cotidiano, mas que guarda muitos aspectos do discurso da ciência, como por exemplo, as referências à metodologia, a intertextualidade com o artigo científico.

Percebemos ainda que a didatização proporcionada pelo uso de aposto e glosa colabora significativamente para que se tenha um discurso pedagógico, que caracteriza o gênero notícias de PC e que o discurso da ciência permanece, mas de uma forma embutida. Mais uma vez, nos amparamos em Bernstein ao afirmar que:

O discurso pedagógico é a comunicação especializada pela qual a transmissão/aquisição diferencial é efetuada. Iniciamos com a questão: "qual discurso está embutido em qual discurso?”.

Definiremos o discurso pedagógico como a regra que embute um discurso de competência (destrezas de vários tipos) num discurso de ordem social, de uma forma tal que o último sempre domina o primeiro (BERNSTEIN, 1996. p. 258).

Para finalizar, entendemos que o processo de didatização do discurso da ciência movimenta diferentes discursos, quais sejam: da ciência, do cotidiano e o jornalístico, implicando uma outra configuração dos gestos de interpretação, uma outra formação de sentidos. Além disso, gostaríamos de esclarecer que os resultados aqui apresentados refletem as análises e reflexões até aqui desenvolvidas, são, portanto, ainda inconclusas.

\section{REFERÊNCIAS}

BAZERMAN, C. Gêneros textuais, tipificação e interação. São Paulo: Cortez, 2005.

BERnstein, B. A Estruturação do Discurso Pedagógico - classe, códigos e controle. Petrópolis: Vozes, 1996.

BRASIL. Ministério da Ciência e Tecnologia. Indicadores Nacionais de Ciência e tecnologia 2005. Brasília: MCT, 2006. Disponível em: http://www.mct.gov.br/upd_blob/0206/206310.pdf. Acesso em: 03 mar. 2010.

CALSAMIGLIA, H. VAN DIKJ, T. Popularization discourse and knowledge about the genome. Discourse \& Society. London: Sage publications, v. 15, n.4, p. 369-389, 2004.

CIAPUSCIO, G. E. Formulation and reformulation procedures in verbal interactions between experts and (semi-)laypersons. Social studies of science, v. 5, n. 2, p. 207-233, 2003.

COLUSSI, L. A reescritura da informação científica em textos de popularização da ciência. 2002. 102 f. Dissertação (Mestrado em Estudos Linguísticos) - Universidade Federal de Santa Maria, Santa Maria, 2002. 
CUENCA, M. J.; BACH, C. Contrasting the form and use of reformulation markers. Discourse Studies, V. 9, n.2, p.149-175, 2007.

DUBOIS, J. et al. Dicionário de Linguística. São Paulo: Cultrix, 1993.

GERHARDT, L.B. A representação dos atores sociais e o processo de reformulação em notícia de popularização científica. In: ENCONTRO DO NÚCLEO DE ESTUDOS AVANÇADOS “LINGUAGEM CULTURA E SOCIEDADE”: GT LABLER, 5, 2009 (no prelo), Santa Maria. Anais. Santa Maria: LABLER/UFSM.

GOMES, I. A. A divulgação científica em Ciência Hoje: características discursivotextuais. Recife: UFPE, 2000. Tese (Doutorado em Linguística), Universidade Federal de Pernambuco, 2000.

HALLIDAY, M. A. K.; MATTHIESSEN, C. M. I. M. Introduction to functional grammar. London: Arnold, 2004.

HILGARTNER, S. The dominant view of popularization: conceptual problems, political uses. Social studies of science, v. 20, n. 3, p. 519-139, 1990.

HYLAND, Ken. Applying a Gloss: Exemplifying and Reformulating in Academic Discourse. Applied Linguistics, v. 28, n.2, Oxford University Press, 266-285, 2007.

Metadiscourse: exploring interaction in writing. London: Continuun, 2005.

Academic discourse. London: Continuun, 2009.

LEIBRUDER, A.P. O discurso de divulgação científica. In: Gêneros do discurso na escola mito, conto, cordel, discurso político e divulgação científica. São Paulo: Cortez, 1999. p. 229253.

MARCUZZO, P.; MOTTA-ROTH, D. Polifonia e avaliação em notícias de popularização da ciência. In: $8^{\circ}$ Círculo de Estudos Linguísticos do Sul (CELSUL), 2008, Porto Alegre. Anais. Porto Alegre: UFRGS/CELSUL, 2008. p. 1-11.

MILLER, B. What does it mean that PRIMES is in P: Popularization and distortion revisited, Social studies of Science, v. 39, n.2, p. 256-288

MOIRAND, S. C. Communicative and cognitive dimensions of discourse on science in the Frech mass media. Discourse Studies, v.5, n.1, p.175-206, 2003.

MOTTA-ROTH, D. Análise crítica de gêneros com foco em artigos de popularização da ciência. Projeto de Produtividade em Pesquisa PQ/CNPq (nº 301962/2007-3), 2008.

.Ciência e mídia: o jogo de vozes em notícias de popularização da ciência. In: V ENCONTRO NÚCLEO DE ESTUDOS LINGUAGEM, CULTURA E SOCIEDADE. 2009, Santa Maria. Anais... Santa Maria, 2009. 
A função avaliativa da polifonia em notícias de popularização da ciência. In: V SIGET- SIMPÓSIO INTERNACIONAL DE ESTUDOS DE GÊNEROS TEXTUAIS, 2009, Caxias do Sul. Resumos... Caxias do Sul: EDUCS, 2009, p.289.

; GERHARDT, L; LOVATO, C. Organização retórica do gênero notícia de popularização da ciência: um estudo comparativo entre português e inglês. In: Círculo de Estudos Lingüísticos do Sul (CELSUL), 8, 2008. Porto Alegre. Anais. Porto Alegre: UFRGS/CELSUL, 2008. 1 CD-ROM.

. A popularização da ciência como processo social: um balanço dos resultados obtidos pelo GT LABLER dentro do projeto PQ/CNPQ n. 301962/2007-3. In: V Encontro do Núcleo de Estudos Linguagem, Cultura e Sociedade: GT LABLER-Módulo 4. Santa Maria, RS: LABLER/PPGL/UFSM, 2009 a.

O conceito de "recontextualização" na teoria social de Basil Bernstein. In: Ciclo de Segundas do LAEL. Palestra realizada na PUCSP, São Paulo, em 29 de maio de 2009 b.

A popularização da ciência como prática social e discursiva. In: ENCONTRO DO NÚCLEO DE ESTUDOS AVANÇADOS “LINGUAGEM CULTURA E SOCIEDADE”: GT LABLER, 5, 2009 c (no prelo), Santa Maria. Anais. Santa Maria: LABLER/UFSM.

Recontextualização do discurso da ciência na mídia eletrônica. Palestra realizada na Jornada de Popularização da Ciência, UNISINOS. São Leopoldo, em 11 jan. 2010 a.

Interação e recontextualização no gênero notícia de popularização científica na internet. In: CONGRESSO INTERNACIONAL LINGUAGEM E INTERAÇÃO II, junho de $2010 \mathrm{~b}$.

; LOVATO, C. dos S. Organização retórica do gênero notícia de popularização da ciência: um estudo comparativo entre Português e Inglês. Linguagem em (Dis)curso, v. 9, n. 2, p. 233-271, 2009.

; MARCUZZO, P. Ciência na mídia: análise crítica de gênero de notícias de popularização científica. Revista Brasileira de Linguística Aplicada, Belo Horizonte. (No prelo).

MUELLER, S. Popularização do conhecimento científico. DataGramaZero - revista de Ciência da Informação - v.3, n. 2, abr, 2002.

MYERS, G. Discourse studies of scientific popularization: questioning the boundaries.

Discourse Studies, v. 5, n. 2, p. 265-279, 2003.

PAGANO, A. Genes, ovelhas e discos compactos: alguns aspectos das reescritas de descobertas científicas. In: MACHADO, I.; L. CRUZ, A.; LYSARDO-DIAS, D. Teorias e práticas discursivas: estudos em análise do discurso. Belo Horizonte: UFMG/Carol Borges, 1998, p. 55-72.

PRATES, Natália Dellagnese; SCHERER, Anelise Scotti; MOTTA-ROTH, Désirée. Organização retórica e uso de aposto em artigos de popularização da ciência. In: 
SEMINÁRIO DO GEL, 56., 2008, Programação... São José do Rio Preto (SP): GEL, 2008. Disponível em: http://www.gel.org.br/?resumo=4929-08 . Acesso em: 28, mar. 2010.

SANTOS, R. L.dos. Expressão metafórica em notícias de popularização da ciência. 91 f. Dissertação (Mestrado em Estudos Linguísticos) - Universidade Federal de Santa Maria, Santa Maria, 2010.

VANDE KOPPLE, W. J. Some exploratory discourse on metadiscourse. College Composition and Communication, v. 36, n.1, p. 82-93, 1985. 